\title{
CLASSIC MAPLE SYRUP URINE DISEASE IN A 46-DAY-OLD BABY: A CASE REPORT
}

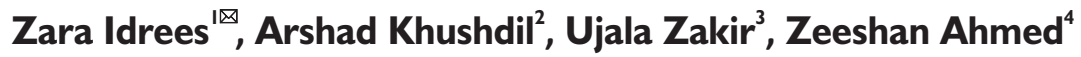

\section{ABSTRACT:}

Maple syrup urine disease (MSUD) is an inborn error of amino acid metabolism secondary to enzyme defect that breaks down branched-chain amino acid (BCAA). Accumulation of these amino acids and their corresponding ketoacids in the body progresses to neurodegenerative disorders and encephalopathy in undiagnosed infants. We report a case of 46 days old baby with classical clinical and biochemical findings consistent with MSUD. Baby was investigated for inborn error of metabolism after he developed lethargy and his oral intake reduced on fifth day of life. A diagnosis of MSUD was established after analysis of plasma and CSF amino acid profile. Baby was treated accordingly and improvement in his condition was seen afterwards.

KEYWORDS: Maple Syrup Urine Disease (MeSH); Amino Acids (MeSH); Amino Acids, Branched-Chain (MeSH); Infant (MeSH); Cerebrospinal Fluid (MeSH).

THIS ARTICLE MAY BE CITED AS: Idrees Z, Khushdil A, Zakir U, Ahmed Z. Classic maple syrup urine disease in a 46-day-old baby: A case report. Khyber Med Univ J 20।8; I0(I):44-46.

\section{INTRODUCTION}

M aple syrup urine disease (MSUD) is an autosomal recessive disorder characterized by malfunctioning of the branched-chain $\alpha$-ketoacid dehydrogenase (BCKAD) complex, that is involved in the catabolism of branched-chain amino acids (BCAAs) which includes leucine, isoleucine and valine. MSUD is marked by elevated levels of branch chain ketoacids in the urine along with elevated branched-chain amino acid (BCAA) in the plasma.

The disease is characterized by feeding difficulty, neurological deficit, encephalopathy and a maple syrup odor of the urine.' MSUD is responsive to dietary restriction. Nutritional management comprises of specially formulated BCAA free food which provides $80 \%$ $90 \%$ of protein and energy needs. ${ }^{2}$ Metabolic acidosis is one of the main causes of neonatal and infant mortality. Survivors inevitably have mental retardation, developmental delay, spastic paralysis, cortical blindness, and other neurologic impairment. ${ }^{3}$

Worldwide incidence of approximately one in 185,000 cases has been reported. ${ }^{4}$ The incidence of MSUD is 9.1\% among other amino acidopathies according to a study conducted in Karachi Pakistan. ${ }^{5}$ Here we are presenting a classic case of MSUD in a 46 days old baby.

\section{CASE REPORT}

A 46-day-old baby boy presented to the Neonatal Intensive Care Unit of Military Hospital, Rawalpindi, in December 2016 with complaints of lethargy and not taking feed since fifth day of life. Baby was born through lower segment caesarian section at a public sector hospital with uneventful antenatal and intra partum history. Baby developed lethargy and decreased oral intake on fifth day of life and was admitted to hospital for 2 days, where he was managed for neonatal sepsis. Baby was discharged on request and brought to our hospital with the manifestation of reduced oral intake, lethargy and unresponsiveness. On presentation, the baby was hypotonic and unresponsive with a score of 3/15 on Glasgow Coma Score (GCS). His weight was $3.0 \mathrm{~kg}$, length was $48 \mathrm{~cm}$ and Occipito-frontal circumference (OFC) was $35 \mathrm{~cm}$, all of which lie at the $50^{\text {th }}$ centile for age and
困 Final Year Student, Army Medical College, Rawalpindi, Pakistan

E-mail: xarkhan2000@gmail.com

2 Military Hospital Rawalpindi, Pakistan.

3 Final Year Student, Army Medical College, Rawalpindi, Pakistan

4 Military Hospital Rawalpindi, Pakistan.

Date Submitted: October II, 2017

Date Revised: January 28, 2018

Date Accepted: February 04, 2018

gender. The baby had diminished reflexes in all four limbs. Pupils were equal bilaterally and reactive to light. The rest of the systemic examination was unremarkable.

Parents of the baby were consanguineously married and he has one normal and healthy male elder sibling. Maternal history of pelvic inflammatory disease, gestational diabetes mellitus, urinary tract infection and drug intake during the pregnancy was absent. During pregnancy mother had her regular antenatal check-up every month during which growth and anomaly scans were done which were normal. Family history was unremarkable. The baby was admitted and empirical treatment for neonatal sepsis, with broad spectrum antibiotics, was started.

Initial laboratory evaluation revealed a normal complete blood count profile, prothrombin time (PT) / activated partial thromboplastin time (APTT), Creactive protein (CRP) and blood glucose levels. Arterial blood gas revealed metabolic acidosis. CSF examination was normal for cell count, proteins and glucose. Workup for an inborn error of metabolism was initiated and revealed a plasma lactate to be mildly elevated and plasma ammonia level was found to be $240 \mu \mathrm{mol} / \mathrm{L}$. His plasma amino acid analysis by ion exchange chromatography showed elevated plasma leucine and isoleucine levels (Table I). CSF was also analyzed by high performance liquid chromatography which revealed abnormal levels of leucine and isoleucine levels, however valine was found to be $<$ I (Table II).

On imaging, CT scan brain revealed hypo-attenuation of white matter in bilateral cerebral hemispheres with effacement of extra cerebral CSF spaces 
TABLE I: PLASMA AMINO ACID ANALYSIS BY ION EXCHANGE CHROMATOGRAPHY

\begin{tabular}{|l|c|c|}
\hline Amino Acid & Plasma levels & Normal levels \\
\hline Leucine & 2303 & $46-147 \mu \mathrm{mol} / \mathrm{L}$ \\
\hline Isoleucine & 373 & $12-77 \mu \mathrm{mol} / \mathrm{L}$ \\
\hline
\end{tabular}

and slit like lateral ventricles suggestive of cerebral edema.

On the basis of plasma and CSF amino acid profiles along with the clinical picture a diagnosis of Maple Syrup Urine Disease was established. MSUD special formula treatment was commenced along with oral Thiamine in the form of injection Neurobion in orogastric (OG) feeds. There was marked improvement in the neurological status of the baby with improvement of GCS to 12/15 on day $8^{\text {th }}$ of hospitalization. The family was counseled regarding the disease prognosis and recurrence in future pregnancies and baby discharged home on MSUD special formula.

\section{DISCUSSION}

MSUD is a rare disorder and thus published reports of diagnosis and treatment usually involve only a few patients and most have focused on management of the acutely ill neonate. ${ }^{6}$ However literature review confirms a case of MSUD in a 2 day old neonate reported in Turkey. Furthermore a retrospective study confirmed 10 cases of MSUD in China. ${ }^{3}$ MSUD has five discrete clinical phenotype namely classic, intermittent, intermediate, thiamine responsive and di-hydrolipoyl dehydrogenase (E3)-deficient, that are genotypically unrelated.

The classic form is manifested in the first week of life with complaints of poor feeding and vomiting that progress to lethargy, convulsions and finally coma. Similarly, our case presented on $5^{\text {th }}$ day of life with lethargy, drowsiness, reduced feed intake and altered GCS score. Most cases of MSUD are often misdiagnosed as neonatal sepsis or meningitis, and death may occur resultantly if untreated. The intermittent form usually affects older children and symptoms become evident during stress situations. Intermediate form of MSUD has less severe presentation with delayed onset of neurological symptoms. ${ }^{8}$ Parents of our case are consanguineously married and studies have proved that consanguinity increase the chance of occurrence of MSUD as it is an autosomal recessive disorder.

The diagnosis of MSUD can be established on the basis of clinical features, elevated BCAAs and branched-chain hydroxyacids and ketoacids in urine. Newborn screening is possible with the help of tandem mass spectrometry which measures the amount of combined leucine-isoleucine concentration in the whole blood and its ratio to other amino acids such as alanine and phenylalanine. Cranial CT scan is helpful in detecting cerebral edema. ' MSUD treatment comprises of a restricted consumption of proteins, with the addition of a semi-synthetic formula of essential amino acids that lacks leucine, isoleucine and valine. Studies have shown that thiamine supplementation helps in lowering the levels of BCAA in plasma. ${ }^{10}$ This treatment plan targets to bring the plasma levels of BCAA within normal ranges, thus downscaling the effects of neurological damage associated mainly with raised leucine levels. ${ }^{4}$ Genetic counseling must be done to reduce occurrence of MSUD.'

MSUD is a rare disease which is difficult to diagnose and even difficult to treat. A high index of suspicion should be kept in mind in order to timely diagnose and manage this otherwise fatal disease.

\section{REFERENCES}

I. Blackburn PR, Gass JM, Vairo FP, Farnham KM, Atwal HK, Macklin S, et al. Maple syrup urine disease: mechanisms and management. Appl Clin Genet 2017;10:57-66. DOI: $10.2147 /$ TACG.SI 25962.

TABLE II: CEREBROSPINAL FLUID AMINO ACID ANALYSIS BY HIGH PERFORMANCE LIQUID CHROMATOGRAPHY

\begin{tabular}{|l|c|c|}
\hline Amino Acid & CSF levels & Normal levels \\
\hline Leucine & 1192 & $12.1-19.3 \mu \mathrm{mol} / \mathrm{L}$ \\
\hline Isoleucine & 171 & $3.9-11.3 \mu \mathrm{mol} / \mathrm{L}$ \\
\hline Valine & $<\mathrm{I}$ & $7.6-18.0 \mu \mathrm{mol} / \mathrm{L}$ \\
\hline
\end{tabular}

2. Van Calcar S. Nutrition Management of Maple Syrup Urine Disease. In: Bernstein L., Rohr F., Helm J. (eds) Nutrition Management of Inherited Metabolic Diseases. 2015, Springer, Cham, Switzerland. DOI:10.1007/978-3319-1462|-8_16.

3. Cheng A, Han L, Feng Y, Li H, Yao R, Wang $D$ et al. MRI and clinical features of maple syrup urine disease: preliminary results in 10 cases. Diagn Interv Radiol 2017; $23: 398-402$. D O I: 10.5152/dir.2017.16466.

4. Chuang DT, Shih VE, Max Wynn R. Maple Syrup Urine Disease (Branched-Chain Ketoaciduria). In: Valle D, Beaudet AL, Vogelstein B, Kinzler KW, Antonarakis SE, Ballabio A, Gibson KM, Mitchell G (Eds). The Online Metabolic and Molecular Bases of Inherited Disease. 2016. McGraw-Hill, New York.

5. Sherazi NA, Khan $A H$, Jafri L, Jamil A, Khan NA, Afroze B. Selective Screening for Organic Acidurias and Amino Acidopathies in Pakistani Children. J Coll Physicians Surg Pak 201 7; 27(4):2 I 8-22I. DOI: 2593.

6. Morton $\mathrm{DH}$, Strauss $\mathrm{KA}$, Robinson DL, Puffenberger EG, Kelley RI. Diagnosis and treatment of maple syrup disease: a study of 36 patients. Pediatrics. 2002; 109(6):999-1008.

7. Köse M, Canda E, Kagnici M, Uçar SK, Çoker M. A Patient with MSUD: Acute Management with Sodium Phenylacetate/Sodium Benzoate and Sodium Phenylbutyrate. Case Rep Pediatr 2017;2017:1045031. DOI: 10.1|55/2017/104503।.

8. Jan W, Zimmerman RA, Wang ZJ, Berry GT, Kaplan PB, Kaye EM. MR diffusion imaging and $M R$ 
spectroscopy of maple syrup urine disease during acute metabolic decompensation. Neuroradiology $2003 ; 45(6): 393-9$. DOI: 10.1007/s00234-003-0955-7

9. Strauss KA, Puffenberger EG, Morton DH. Maple Syrup Urine
Disease. 2006 Jan 30 [Updated 2013 May 9]. In: Adam MP, Ardinger $\mathrm{HH}$, Pagon RA, et al., editors. GeneReviews ${ }^{\circledR}$ [Internet]. Seattle (WA): University of Washington, Seattle; 1993-2018. Available from: https://www.ncbi.nlm.nih.gov/boo $\mathrm{ks} / \mathrm{NBK} \mid 319 /$

I0. Scriver CR, Mackenzie S, Clow CL, Delvin E. Thiamine-responsive maple-syrup-urine disease. Lancet I97I;I(7694):3I0-2.

\section{AUTHOR'S CONTRIBUTION}

All authors (ZI, AK, UZ, ZA) have made substantial contributions to the manuscript; literature review, drafting the manuscript, critical review \& final approval of the version to be published

Authors agree to be accountable for all aspects of the work in ensuring that questions related to the accuracy or integrity of any part of the work are appropriately investigated and resolved.

This is an Open Access article distributed under the terms of the Creative Commons Attribution-NonCommercial-NoDerivatives 4.0 International License (https://creativecommons.org/licenses/by-nc-nd/4.0/) which permits to reproduce freely in any medium and share the Licensed Material, for NonCommercial purposes only, provided the original work is properly cited. 